\title{
Co-crystals of diflunisal and isomeric pyridinecarboxamides - a thermodynamics and crystal engineering contribution
}

\author{
António O. L. Évora ${ }^{a *}$, Ricardo A. E. Castro $^{b}$, Teresa M. R. Maria ${ }^{a}$, M. Ramos Silva ${ }^{c}$, J. H. ter Horst ${ }^{d}$, João \\ Canotilho $^{\mathrm{b}}$ and M. Ermelinda S. Eusébio ${ }^{\mathrm{a}}$ \\ ${ }^{a}$ Department of Chemistry, University of Coimbra, 3004-535 Coimbra, Portugal \\ ${ }^{b}$ Faculty of Pharmacy, University of Coimbra, Portugal \\ ${ }^{c}$ Department of Physics, University of Coimbra, Portugal \\ ${ }^{d}$ EPSRC Centre for Innovative Manufacturing in Continuous Manufacturing and Crystallisation (CMAC), \\ Strathclyde Institute of Pharmacy and Biomedical Sciences (SIPBS), Technology and Innovation Centre, \\ University of Strathclyde, 99 George Street, Glasgow G1 1RD, U.K.
}

To whom correspondence should be addressed. E-mail: antonio.evora@uc.pt Tel.: $+351239854450$

\section{ABSTRACT}

Diflunisal is an anti-inflammatory non-steroidal drug, class II of the Biopharmaceutical Classification System, that has recently been the subject of renewed interest due to its potential use in the oral therapy of familial amyloid polyneuropathy. In this work, a thermodynamic based approach is used to investigate binary mixtures (diflunisal + picolinamide) and (diflunisal + isonicotinamide) in order to identify solid forms potentially useful to improve the biopharmaceutical performance of this active pharmaceutical ingredient. Special emphasis is put on the research of co-crystals and on the influence of structural changes in the pyridinecarboxamide co-former molecules on co-crystal formation with diflunisal. The thermodynamic based methodology described by ter Horst et al. in 2010 indicates that the formation of co-crystals is thermodynamically feasible for both systems. The binary solid-liquid phase diagrams are built and allow identifying unequivocally the formation of co-crystals of diflunisal with each of the two isomers and also their stoichiometry: 1:1, (diflunisal:co-former) in the case of pyridine-2-carboxamide, picolinamide, and (2:1) for pyridine-4-carboxamide, isonicotinamide. Two binary eutectic mixtures, potentially relevant for pharmaceutical application, are also identified. Infrared spectroscopy allows the identification of the acid...N-pyridine heterosynthon in the three co-crystals formed by diflunisal with the isomeric pyridinecarboxamides. However, the results differentiate clearly pyridine-2-carboxamide from pyridine-3carboxamide and pyridine-4-carboxamide which share similar crystalline arrangements at least in what concerns the supramolecular synthons. 


\section{Introduction}

Co-crystals ${ }^{1-6}$ have been the subject of intense research in the last decade, due to their great potential for practical applications in several domains, ${ }^{7,8}$ especially when active pharmaceutical ingredients, APIs, are concerned 5, 9, 10. Pharmaceutical co-crystals, combining an API and an acceptable co-former, ${ }^{11}$ have the potential for enhancing the physical properties of the API, positively impacting its solubility, stability, oral bioavailability and processability, without compromising its biological function 1, 9, 12-21. Thus, co-crystal research formation spurs interest from pharmaceutical industry, especially for those APIs whose oral bioavailability is solubility limited, classes II and IV of the Biopharmaceutical Classification System (BCS) ${ }^{22}$. For this kind of drugs, besides cocrystals, binary eutectic mixtures, for instance, are also relevant ${ }^{23-26}$ due to their increased surface area and the potential for increasing dissolution rate. Therefore, the establishment of the binary solid-liquid phase diagrams of the API and the potential co-former is of considerable interest as it gives comprehensive information of the solid binary mixtures behavior.

Diflunisal, DIF, Figure 1.a, BCS class II nonsteroidal anti-inflammatory drug, finds application in medical practice in oral formulations for the acute or long-term treatment of rheumatoid arthritis, osteoarthritis, or mild to moderate pain ${ }^{27}$, and research is currently been carried out on its use in familial amyloid polyneuropathy ${ }^{28}$. Pyridinecarboxamides such as nicotinamide, NA, and the isomeric picolinamide, PA, and isonicotinamide, INA, (Figure 1) are quite appealing as co-formers, $\mathrm{CoF}$, for target compounds with carboxylic acid groups, as association through different supramolecular heterosynthons can occur, envisaging the possibility of formation of co-crystals of different stoichiometry ${ }^{29}$. In a previous study carried out by this research team on the DIF + NA system, a 2:1 co-crystal was identified ${ }^{30,31}$, and the presence of the acid $\cdots \mathrm{N}$-pyridine heterosynthon in the cocrystal structure was confirmed. Wang et al. ${ }^{32}$ obtained a 2:1 DIF + NA co-crystal from equimolar ethanol solutions, and in the same experimental conditions a 2:1 DIF + INA cocrystal. PA and INA differ from nicotinamide just on the amide group position relatively to the ring nitrogen (ortho, para, meta, respectively in PA, INA and NA). The proximity between the amide hydrogen and the heterocyclic nitrogen in PA, enabling intramolecular hydrogen bonding, has been regarded to contribute to a lower ability of PA to co-crystal formation $^{33,34}$.

Thermodynamic and crystal engineering principles are of fundamental relevance in order to control and predict crystallization process outcomes and co-crystal properties. 
Some work has been published concerning the use of solubility measurements and ternary phase diagrams for co-crystal formation prediction and for design of rational preparative procedures from solutions ${ }^{30,34-38}$. A systematic study of co-crystal formation in series of structurally related co-formers will contribute to the identification of thermodynamic and crystal engineering principles for co-crystal production and application.

The current work therefore follows our interest in diflunisal multicomponent systems $11,30,31$, and on the different pyridinecarboxamides as co-formers ${ }^{34,39}$ : a thermodynamic based approach, including binary and ternary solid-liquid phase diagram establishment, is used in order to investigate solid forms for potential improvement of physical and chemical properties of the API. The influence of structural changes in the pyridinecarboxamide co-former molecules on co-crystal formation with diflunisal is discussed.

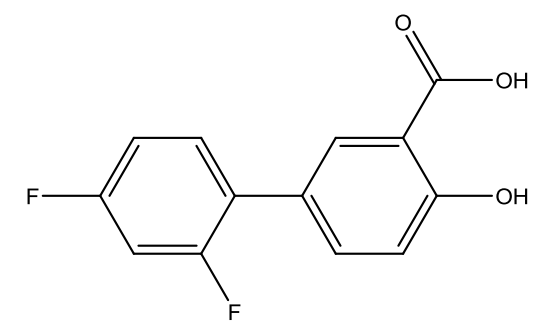

a)<smiles>NC(=O)c1ccccn1</smiles>

b)<smiles>NC(=O)c1cccnc1</smiles>

c)<smiles>NC(=O)c1ccncc1</smiles>

d)

FIGURE 1. Molecular structure a) Diflunisal; b) Picolinamide (pyridine-2-carboxamide) c) Nicotinamide (pyridine-3-carboxamide); d) Isonicotinamide (pyridine-4-carboxamide).

\section{Experimental}

\subsection{Materials and mixtures preparation}

The starting materials were supplied by Aldrich with specified purify 0.99 . XRPD confirmed diflunisal as the triclinic polymorph $\mathrm{I}^{40}$, and picolinamide as polymorph II $^{41,42}$. The room temperature thermodynamic stable isonicotinamide polymorph II (reference code EHOW1H01) ${ }^{43-46}$ was used in this work experiments. For the preparation of mixtures of different composition the appropriate amounts of each substance were weighted in a Mettler balance M163 ( $\pm 0.01 \mathrm{mg}$ ) and then mixed in a Retsch MM 400 ball mill, in 10 $\mathrm{mL}$ stainless steel jars with two $7 \mathrm{~mm}$ stainless steel balls, for 30 minutes at a $15 \mathrm{~Hz}$ 
frequency. For diflunisal + picolinamide, grinding was assisted by ethanol $(10 \mu \mathrm{l})$, in most experiments, and for diflunisal + isonicotinamide neat grinding was carried out. Similar grinding experiments performed on the pure materials result in conversion of diflunisal from form I to form III ${ }^{40}$ in ethanol assisted grinding experiments ${ }^{30}$, while no changes were observed relatively to pure components' starting solid forms in all other experiments (results confirmed by XRPD).

\subsection{Co-crystal screening}

Crystal16 equipment by Avantium Technologies was used in order to determine saturation temperatures of pure components in ethanol and of mixtures of diflunisal with isonicotinamide or picolinamide in the same solvent. The equipment allows measuring cloud and clear points, based on turbidity, of sixteen $1 \mathrm{~mL}$ solution aliquots in parallel and automatically. The clear point temperature is the temperature at which a suspension becomes a clear solution upon slowly heating. The clear point temperature upon heating solution aliquots of beforehand established composition at a $0.3 \mathrm{~K} \cdot \mathrm{min}^{-1}$ temperature scanning rate was determined and taken as the saturation temperature of the used composition. The significance in the clear point temperatures of a single sample was less than $2^{\circ} \mathrm{C}$ in subsequent measurements.

Ethanol was used, as it is a solvent of choice in pharmaceutical development: it belongs to class 3 of the residual solvents classification (low toxic potential) ${ }^{42,43}$, allowing also to achieve adequate drying of the solid samples at low temperatures.

\subsection{Differential scanning calorimetry (DSC)}

The studies were performed on a PerkinElmer Pyris1 power compensation calorimeter with an intracooler cooling unit at $248 \mathrm{~K}$ (ethylene glycol + water, 1:1 (v/v), cooling mixture). The samples, mass $\sim 2 \mathrm{mg}$, were hermetically sealed in $30 \mu \mathrm{L}$ aluminum pans, and an empty pan was used as reference. A $20 \mathrm{~mL} \cdot \mathrm{min}^{-1}$ nitrogen purge was employed. Scanning rates $\beta=10 \mathrm{~K} \cdot \mathrm{min}^{-1}$ and $\beta=2 \mathrm{~K} \cdot \mathrm{min}^{-1}$ were used. Temperature calibration ${ }^{47,48}$ was performed with the high-grade standards: biphenyl (CRM LGC 2610, $T_{\text {fus }}=(342.08 \pm$ $0.03) \mathrm{K})$, benzoic acid (CRM LGC 2606, $\left.T_{\text {fus }}=(395.50 \pm 0.02) \mathrm{K}\right)$, indium (Perkin-Elmer, $\mathrm{x}=0.9999, T_{\text {fus }}=429.75 \mathrm{~K}$ ), and caffeine (Mettler Toledo calibration substance, ME 18 $\left.872, T_{\text {fus }}=(509.75 \pm 0.2) \mathrm{K}\right)$. Enthalpy calibration was performed with indium $\left(\Delta_{\text {fus }} H_{\mathrm{m}}=\right.$ $\left.3286 \pm 13 \mathrm{~J} \cdot \mathrm{mol}^{-1}\right)^{47}$ and verified with the fusion enthalpy of biphenyl $\left(\Delta_{\text {fus }} H_{\mathrm{m}}=18574 \pm 4\right.$ 
$\left.\mathrm{J} \cdot \mathrm{mol}^{-1}\right)^{47}$ and benzoic acid $\left(\Delta_{\text {fus }} H_{\mathrm{m}}=18063 \pm 42 \mathrm{~J} \cdot \mathrm{mol}^{-1}\right)^{47}$. The uncertainties of the measurements are estimated to be $\pm 0.2 \mathrm{~K}$ for temperature and $\pm 2 \%$ for enthalpy.

\subsection{Infrared spectroscopy (FTIR)}

The IR spectra were collected, with $1 \mathrm{~cm}^{-1}$ spectral resolution, on a ThermoNicolet IR300 Fourier transform infrared spectrometer, equipped with a deuterated triglycine sulfate (DTGS) detector and a $\mathrm{Ge} / \mathrm{KBr}$ beam splitter, using the $\mathrm{KBr}$ pellet technique.

\section{$2.5 X$-ray Power diffraction (XRPD)}

A Bruker-AXS D2 Phaser X-ray powder diffractometer, Bragg-Brentano geometry, was used with Ni-filtered $\mathrm{Cu} \mathrm{K \alpha},(\lambda=1.54184 \AA$ A) radiation and a Lynxeye detector. A rotating glass capillary ENRAF-NONIUS powder diffractometer, equipped with a CPS120 detector by INEL, was also employed with data collection in Debye-Scherrer geometry, using monochromatized $\mathrm{CuK} \alpha_{1}$ radiation $(\lambda=1.540598 \AA)$. Silicon was used as an external calibrant.

\section{Results and discussion}

\subsection{Co-crystal screening}

The ability of co-crystal formation of diflunisal (DIF) with isonicotinamide (INA) and picolinamide (PA) is confirmed by applying the methodology described by ter Horst et al. ${ }^{34,37}$, using clear point temperature measurements of suspensions in ethanol. In a first step of this procedure, the solubility of the pure compounds in ethanol was determined. The saturation temperatures obtained for different solution concentrations could be well correlated to the simplified van't Hoff equation (1) as shown in Figure 2.

$$
\ln x=-\Delta H / R\left(1 / T-1 / T_{0}\right)
$$

The variables $\Delta H / R$ and $\Delta H / R T_{0}$ are used as fitting parameters and their fitted values are presented in table 1. For the co-formers the solubilities are in good agreement with what was previously obtained by ter Horst et al. ${ }^{37}$. XRPD confirms DIF form III as the solid phase in equilibrium with the solutions and for the co-formers INA, form I (contaminated with form II) and PA form II were obtained (Figure S1, supplementary material).

In a second step, the saturation temperatures, $T_{\mathrm{s}}$, of mixtures of composition $\left(x_{\mathrm{DIF}}{ }^{*}, x_{\mathrm{CoF}}{ }^{*}\right)$ are determined after dissolution and recrystallization, using ethanol as the solvent. The 
pure component saturation concentrations $x_{\mathrm{DIF}} *$ and $x_{\mathrm{CoF}} *$ were interpolated or extrapolated from the van't Hoff fitting, both at a reference temperature $T_{\text {ref }}$. The resulting saturation temperatures $T_{\mathrm{s}}$ are compared with the reference temperatures, $T_{\text {ref, }}$ used to make the sample composition $\left(x_{\mathrm{DIF}}{ }^{*}, x_{\mathrm{CoF}}{ }^{*}\right)$. If diflunisal and the co-formers are able to form a stable co-crystal, then the $T_{\mathrm{s}}$ of the co-crystal in the mixed solutions should be higher than the $T_{\text {ref }}$ ${ }^{37}$. This was observed in both cases as shown in Figure 3, where data for NA ${ }^{30}$ were also included.

The observed temperature differences $\left(T_{\mathrm{S}}-T_{\text {ref }}\right)$ are very high, above $48 \mathrm{~K}$ for all three systems. This large temperature difference indicates not only that co-crystal formation is highly likely, but also that the resulting co-crystals are very stable. In the Xray powder diffractograms of the obtained recrystallized solids after the saturation temperature measurements, new reflections are further evidence that a new solid entity is formed (Figure S2, supplementary material).

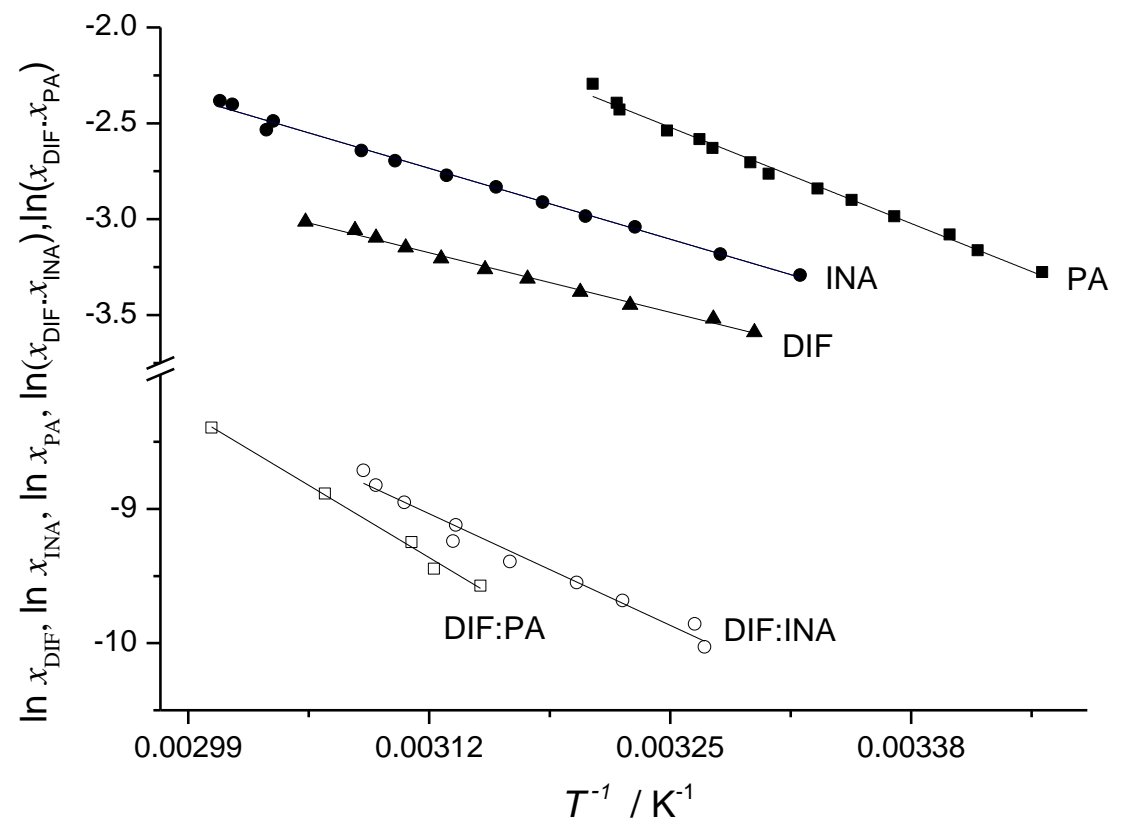

FIGURE 2. The van't Hoff plot of DIF ( $\mathbf{\Delta})$. INA(•), PA ( $\bullet$ ) and DIF:INA (०) and DIF:PA ( $\square)$ cocrystals in ethanol; $x_{\mathrm{DIF}}, x_{\mathrm{INA}}, x_{\mathrm{PA}}$, are the mole fractions of respectively DIF, INA and PA in the ethanolic solutions 
TABLE 1. Parameters of the van't Hoff equation for diflunisal, isonicotinamida and picolinamide and for the co-crystals DIF + INA and DIF + PA, in ethanol.

\begin{tabular}{ccc}
\cline { 2 - 3 } & $(\Delta H / R) / \mathrm{K}$ & $\Delta H / R T_{0}$ \\
\hline DIF & $(2.4 \pm 0.1) \times 10^{3}$ & $4.3 \pm 0.2$ \\
INA & $(2.8 \pm 0.1) \times 10^{3}$ & $6.0 \pm 0.2$ \\
PA & $(3.9 \pm 0.1) \times 10^{3}$ & $10.1 \pm 0.3$ \\
DIF : INA & $(6.4 \pm 0.3) \times 10^{3}$ & $11 \pm 1$ \\
DIF : PA & $(8.3 \pm 0.3) \times 10^{3}$ & $17 \pm 1$ \\
\hline
\end{tabular}

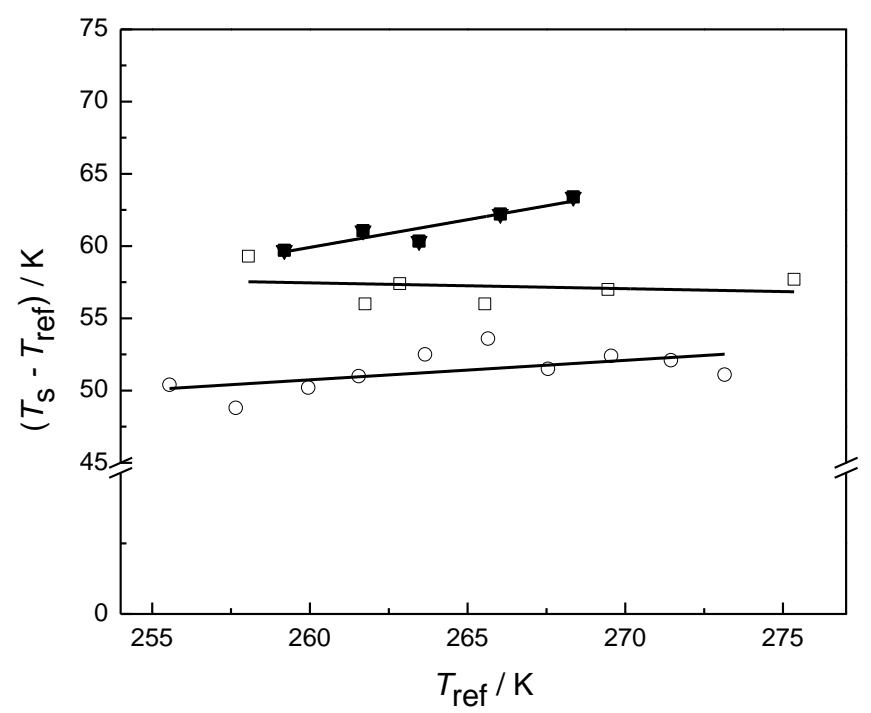

FIGURE 3. Temperature difference $\left(T_{\mathrm{s}}-T_{\text {ref }}\right)$ between the measured saturation temperature $T_{\mathrm{s}}$ of samples of composition $\left(x_{\mathrm{DIF}}^{*}\left(T_{\text {ref }}\right), x_{\mathrm{CoF}} *\left(T_{\text {ref }}\right)\right)$, versus $T_{\text {ref. }}$ The mole fractions $x_{\mathrm{DIF}} *\left(T_{\text {ref }}\right)$ and $x_{\mathrm{CoF}} *\left(T_{\text {ref }}\right)$ indicate the solubility of respectively DIF and CoF at the reference temperature $T_{\text {ref. }}(\boldsymbol{\nabla})$ $\mathrm{DIF}+\mathrm{NA}^{30}$; ( $)$ DIF + INA; ( $\left.\square\right) \mathrm{DIF}+\mathrm{PA}$.

From the van't Hoff plots shown in Figure 2 for DIF:INA and DIF:PA in ethanol, the parameters presented in Table 1 were obtained. These were used to draw estimates of the isothermal ternary phase diagrams for DIF:INA and DIF:PA in ethanol at $298 \mathrm{~K}$ and 323 K, Figure 4. Both co-crystals are very stable and may be obtained by addition of small amount of the co-formers to the API saturated solutions. The composition of the 3-phase equilibrium points shown in Figure 4 for the DIF+INA+ethanol system are $\left(x_{\mathrm{DIF}}=7.6 \times 10^{-4}\right.$; $\left.x_{\mathrm{INA}}=3.3 \times 10^{-2}\right)$ and $\left(x_{\mathrm{DIF}}=2.4 \times 10^{-2} ; x_{\mathrm{INA}}=1.1 \times 10^{-3}\right)$, at $25^{\circ} \mathrm{C}$ and $\left(x_{\mathrm{DIF}}=1.9 \times 10^{-3} ; x_{\mathrm{INA}}\right.$ $\left.=7.0 \times 10^{-2}\right)$ and $\left(x_{\mathrm{DIF}}=4.4 \times 10^{-2} ; x_{\mathrm{INA}}=3.1 \times 10^{-3}\right)$ at $50{ }^{\circ} \mathrm{C}$. For DIF+PA+ethanol the corresponding values are $\left(x_{\mathrm{DIF}}=2.4 \times 10^{-4} ; x_{\mathrm{PA}}=5.2 \times 10^{-2}\right)$ and $\left(x_{\mathrm{DIF}}=2.4 \times 10^{-2} ; x_{\mathrm{PA}}=5.3 \times 10^{-4}\right.$ ), at $25^{\circ} \mathrm{C}$ and $\left(x_{\mathrm{DIF}}=7.3 \times 10^{-4} ; x_{\mathrm{PA}}=1.4 \times 10^{-1}\right)$ and $\left(x_{\mathrm{DIF}}=4.4 \times 10^{-2} ; x_{\mathrm{PA}}=2.4 \times 10^{-3}\right)$ at $50{ }^{\circ} \mathrm{C}$. From the phase diagram it is apparent that the compositional region for obtaining co- 
crystal is very large: there is thus a large freedom in the choice for solution composition during co-crystal production.
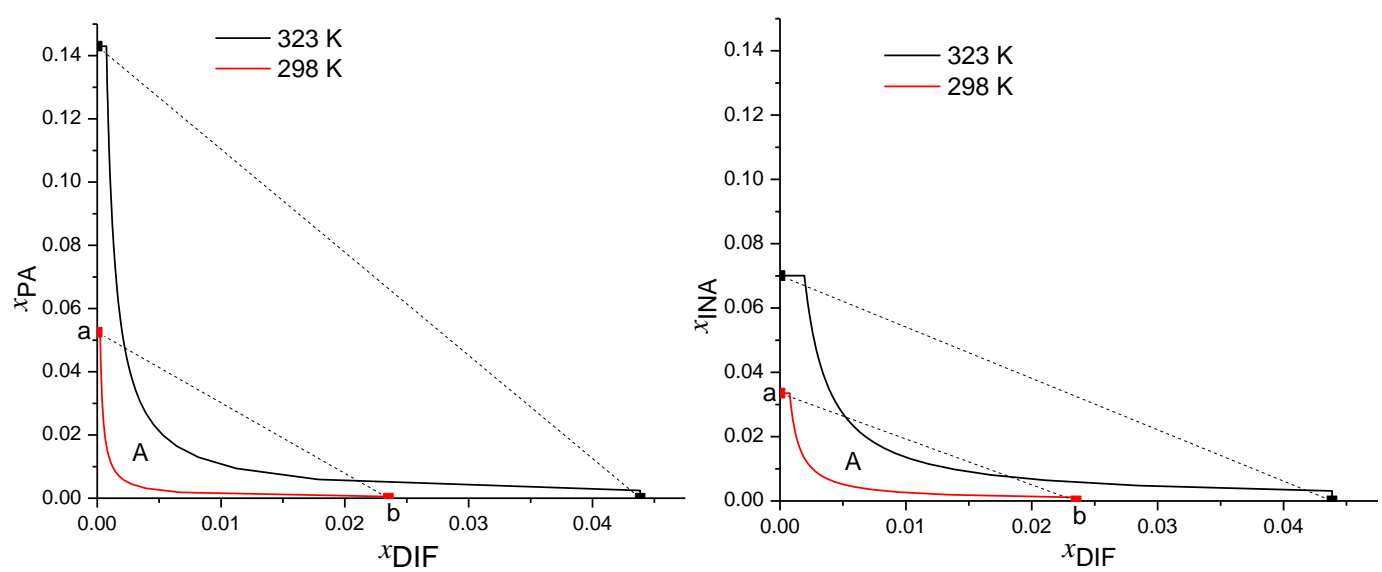

FIGURE 4. Estimated isothermal ternary phase diagrams for a) DIF+PA and b) DIF+INA in ethanol at 298 and $323 \mathrm{~K}$. The curved part of the lines gives co-crystal solubility.

\section{2 (Solid + liquid) binary phase diagrams}

Binary (solid + liquid) phase diagrams are conclusive evidence of co-crystal or salt formation, allowing the determination of their stoichiometry. Salt formation is not expected for the systems under investigation due to the $\mathrm{pKa}$ differences between the components: $\Delta$ pKa INA-DIF $=0.4 ; \Delta$ KKapA-DIF $=-1.4^{20,23,24,49,50}$. Additionally, from these diagrams, other mixture compositions, such as the binary eutectic mixtures, which may also be of interest in pharmaceutical formulations due to their potential increased dissolution rate, can also be identified ${ }^{24-26,30,51,52}$ In the construction of binary (solid + liquid) phase diagrams for (DIF + INA) and (DIF + PA) systems, DSC measurements on mixtures of different composition prepared by grinding were performed.

$\underline{\text { Diflunisal }+ \text { isonicotinamide }}$

Illustrative DSC thermograms obtained for different mixtures of DIF + INA are presented in Figure 5. 


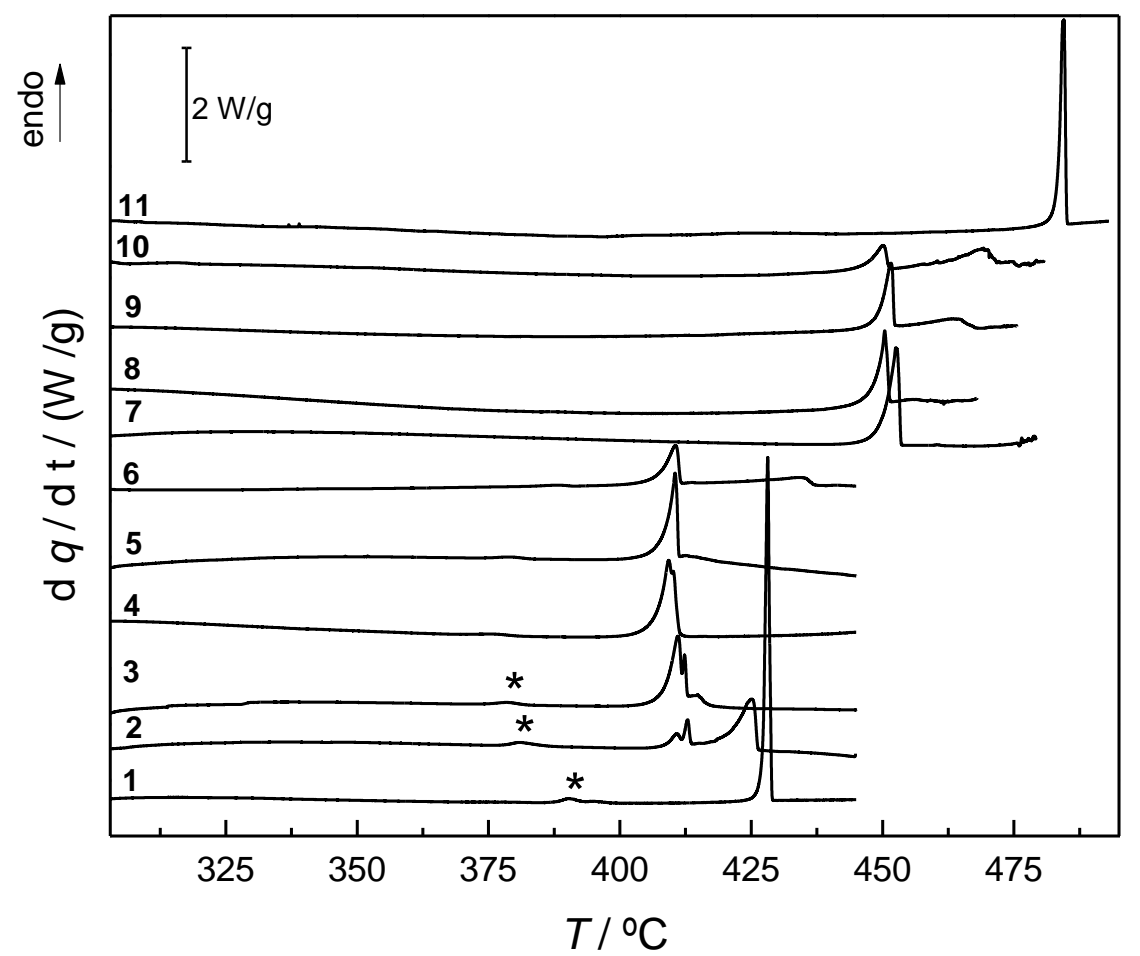

FIGURE 5. DSC heating curves for selected DIF + INA mixtures at a heating rate $\beta=2 \mathrm{~K} \mathrm{~min}^{-1}$. 1. $x_{\mathrm{DIF}}=0$; 2. $x_{\mathrm{DIF}}=0.0502 ;$ 3. $x_{\mathrm{DIF}}=0.1667$; $. x_{\mathrm{DIF}}=0.1999 ;$ 5. $x_{\mathrm{DIF}}=0.2501 ;$ 6. $x_{\mathrm{DIF}}=0.4004 ; 7$. $x_{\mathrm{DIF}}=0.6667 ; 8 . x_{\mathrm{DIF}}=0.7484 ;$ 9. $x_{\mathrm{DIF}}=0.7996 ; 10 . x_{\mathrm{DIF}}=0.8572 ; 11 . x_{\mathrm{DIF}}=1.000 . *_{-}$ isonicotinamide II $\rightarrow$ I transition.

A single narrow peak is observed in the thermogram of the $x_{\mathrm{DIF}}=0.6667$ mixture, as expected for a 2:1 DIF:INA co-crystal, with melting temperature $T_{\text {fus }}=(452.2 \pm 0.3) \mathrm{K}$ and a heat of fusion $\Delta_{\text {fus }} H_{\mathrm{m}}=(88.6 \pm 1.8) \mathrm{kJ} \cdot \mathrm{mol}^{-1}$, averaged over $n=6$ experiments.

In the DSC curves for mixtures that contain an excess of the co-former, $x_{\mathrm{DIF}}<0.6667$, two invariant points at $T_{\mathrm{E} 1}=(406.3 \pm 2.2) \mathrm{K}$ and $T_{\mathrm{E} 2}=(412.3 \pm 0.6) \mathrm{K}$ are observed. These are ascribable to two eutectic points involving different INA polymorphs and the co-crystal. INA form II, the starting material, has a solid-solid phase transition on heating, Figure 5, curve 1 (marked by a $*$ ), giving rise to form I, as already described in literature ${ }^{45}$ and confirmed in our laboratory. The form I melting temperature is $T_{\text {fus }}=(428.7 \pm 0.5) \mathrm{K}$ and heat of fusion $\Delta_{\mathrm{fus}} H_{\mathrm{m}}=(22.9 \pm 0.5) \mathrm{kJ} \cdot \mathrm{mol}^{-1}$. For $x_{\mathrm{DIF}}>0.6667$, figure 5 , a new invariant point is observed at $T_{\mathrm{E} 3}=(450.4 \pm 1.3) \mathrm{K}$.

The binary solid-liquid phase diagram for (DIF + INA) derived from DSC data is shown on Figure 6. The solidus curve in the diagram is obtained from the onset temperature, $T_{\mathrm{E}}$, of the first peak and the liquidus curve from the peak temperature, $T_{\text {liq }}$, of the last peak observed in each DSC thermogram ${ }^{53,54}$. Maximum uncertainties on the temperature values are $\pm 0.8 \%$. These results are shown in table $\mathrm{S} 1$ for (diflunisal + isonicotinamide). 


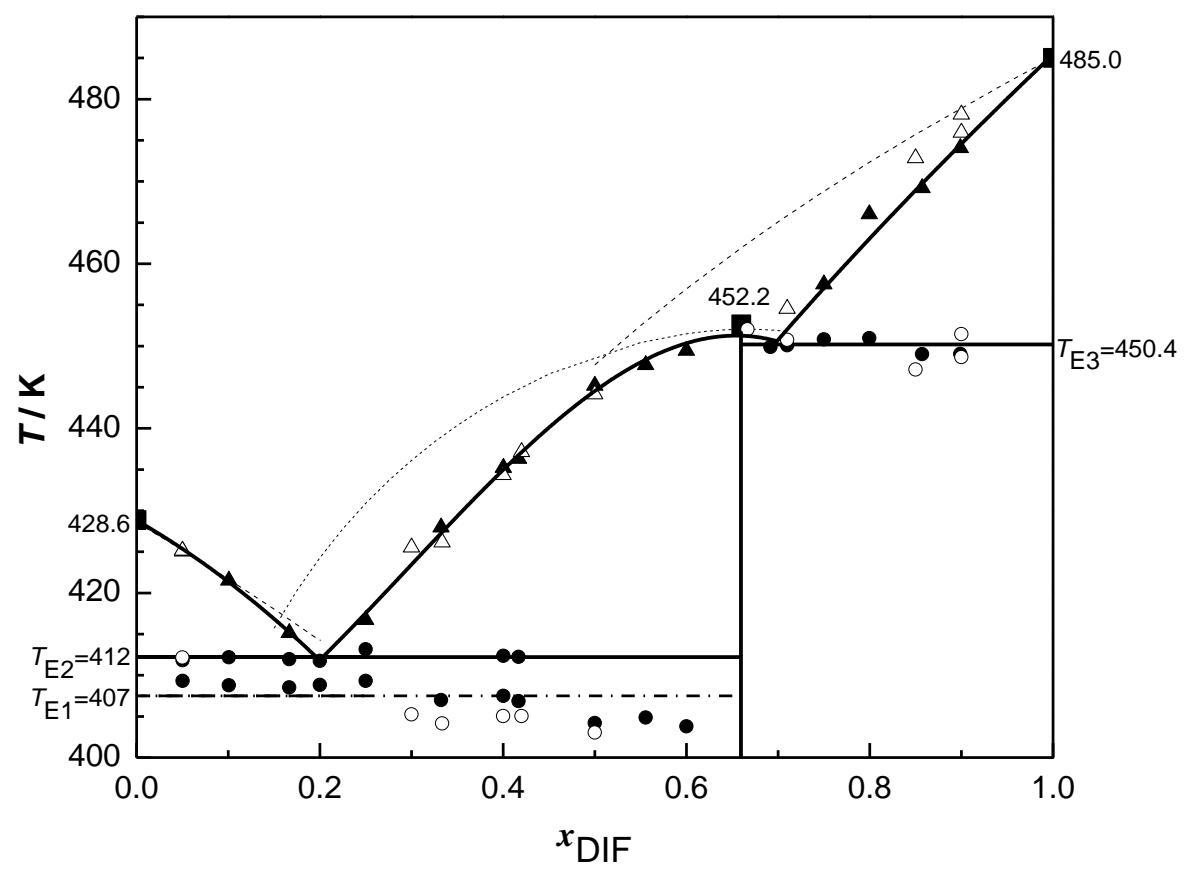

FIGURE 6. (Solid + liquid) phase diagram of (DIF + INA). $\bullet$, o, eutectic temperature, $\boldsymbol{\Delta}, \Delta$, liquidus temperature, $\mathbf{\square}$, pure compound fusion. (solid symbols, $\beta=2 \mathrm{~K} \cdot \mathrm{min}^{-1}$, empty symbols, $\beta=$ $\left.10 \mathrm{~K} \cdot \mathrm{min}^{-1}\right)$; solid lines are used as guides for the eye; dotted lines represent ideal behavior.

The enthalpies of fusion of the eutectic peaks in the DSC curves of mixtures of different compositions were used to construct the triangular Tammann plots shown in Figure 7. Tammann plots are normally used in order to define the eutectic compositions and to evaluate the possibility of solid solution formation. ${ }^{51,55}$ The enthalpy values used in Figure 7 were obtained by deconvolution of the complex DSC curves registered at $\beta=2 \mathrm{~K} \cdot \mathrm{min}^{-1}$ (Uncertainties in these enthalpy values are at maximum $\pm 5 \%$ ). For mixtures with $x_{\mathrm{DIF}} \leq 0.6667$, Figure 7.a, the sum of the enthalpies of both invariant temperature peaks at $T_{\mathrm{E} 1} \sim 406 \mathrm{~K}$ and $T_{\mathrm{E} 2} \sim 412.3 \mathrm{~K}$ was used. The fitted straight lines defining the Tammann triangle, Figure 7.a, intercept the composition axis at $x_{\mathrm{DIF}}=0$ and $x_{\mathrm{DIF}}=0.6667$ (the exact co-crystal composition) as expected if no solid solutions are formed (otherwise zero eutectic melting enthalpy will be observed at other composition). The eutectic composition is found at the apex of the triangle as $x_{\mathrm{DIF}}=0.20$. For mixtures with $x_{\mathrm{DIF}} \geq$ 0.6667 , Figure 7.b, the enthalpy of the invariant temperature peaks at $T_{\mathrm{E} 3} \sim 450 \mathrm{~K}$ was used. The eutectic composition is too close to the co-crystal composition and from the data it is not possible to obtain a precise value. The Tammann plot gives evidence of the expected evolution of the enthalpy of fusion of the eutectic mixture as diflunisal content increases. No evidence of solid solution formation is found for diflunisal rich mixtures (interception of the straight line with the composition axis at $x_{\mathrm{DIF}}=1$ ). 


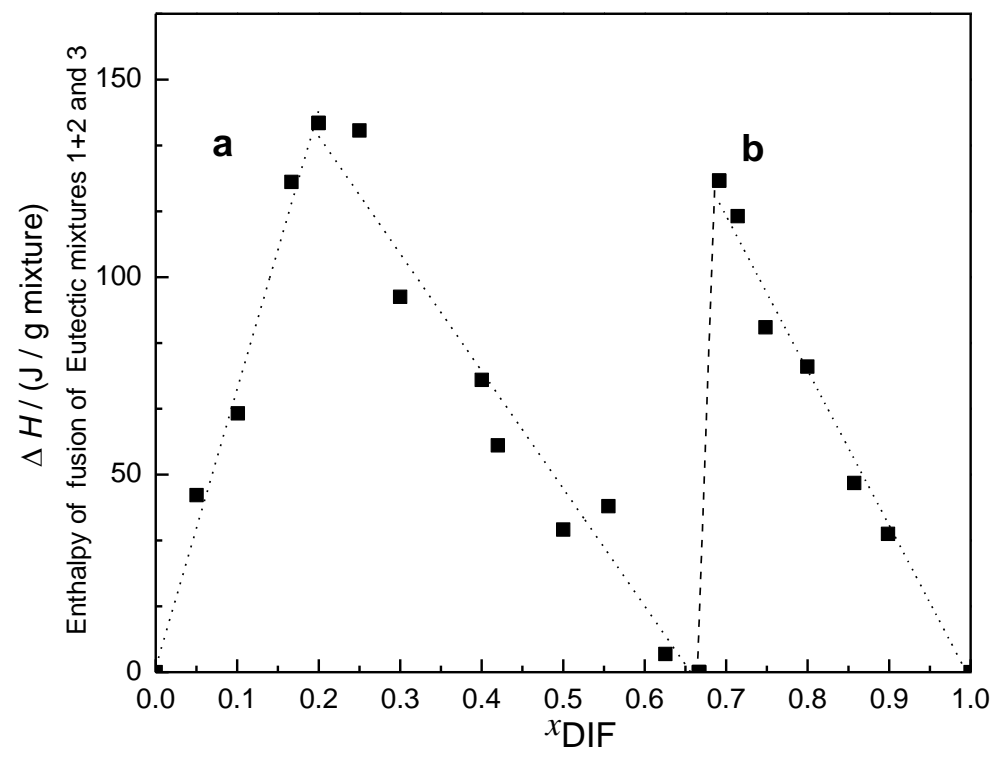

FIGURE 7. Tammann plots for the (diflunisal + isonicotinamide) system a. $x_{\mathrm{DIF}} \leq 0.6667$ b. $x_{\mathrm{DIF}} \geq$ 0.6667 .

Assuming complete immiscibility in the solid phase and total miscibility in the liquid one, and that the enthalpy of fusion does not change in the temperature range considered, the liquidus temperatures $T_{\text {fus, } \text {, }^{*}}$ for compositions where an excess of a pure component $i$ is present can be calculated using eq. $(2)^{56}$.

$$
\frac{1}{T_{f u s}}=\frac{1}{T_{f u s, i^{*}}}-\frac{R}{\Delta_{f u s} H_{m, i^{*}}} \ln x_{i} \gamma_{i}
$$

$T_{\text {fus }}$ is the liquidus temperature of a mixture of mole fraction $x_{\mathrm{i}}$ of component $i$, whose fusion temperature and molar enthalpy of fusion, when pure, are $T_{\mathrm{fus}, \mathrm{i}}{ }^{*}$ and $\Delta_{\mathrm{fus}} H_{\mathrm{m}, \mathrm{i}^{*}}$, respectively, and $\gamma_{\mathrm{i}}$ is the activity coefficient of $i$ in the liquid solution. Taking $T_{\text {fus,DIF }}{ }^{*}=$ $(485.0 \pm 0.5) \mathrm{K}$ and $\Delta_{\text {fus }} H_{\mathrm{m}, \mathrm{DIF}}{ }^{*}=(35.6 \pm 1.0) \mathrm{kJ} \cdot \mathrm{mol}^{-1}$, the activity coefficients of diflunisal were calculated and the values found to range from $\gamma_{\mathrm{DIF}}=0.90$ for $x_{\mathrm{DIF}}=0.8988$ to $\gamma_{\mathrm{DIF}}=0.76$ for $x_{\mathrm{DIF}}=0.7484$, reflecting a negative deviation from ideal behavior, indicating significant intermolecular interactions between both compounds in the liquid phase. In the isonicotinamide rich region of the diagram the deviation from ideality is much lower with $\gamma_{\mathrm{INA}}=0.99$ for $x_{\mathrm{DIF}}=0.0502$ and $\gamma_{\mathrm{INA}}=0.98$ for $x_{\mathrm{DIF}}=0.1667\left(T_{\text {fus,INA }} *=\right.$ $(428.6 \pm 0.5) \mathrm{K}$ and $\Delta_{\text {fus }} H_{\mathrm{m}, \mathrm{INA}}{ }^{*}=(22.9 \pm 0.5) \mathrm{kJ} \cdot \mathrm{mol}^{-1}$ were used in the calculations $)$. Ideal behaviour was calculated, for diflunisal compositions between both eutectic points, using equation (3) ${ }^{56}$, with the experimental fusion data for the co-crystal, $T_{\text {fus,DIF:INA }}$ and

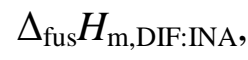




$$
\frac{1}{T_{f u s}}=\frac{1}{T_{f u s, \mathrm{DIF}: \mathrm{INA}}}-\frac{R}{\Delta_{f u s} H_{m, \mathrm{DIF}: \mathrm{INA}}}\left\{\ln \left[x_{\mathrm{DIF}}^{2} \cdot\left(1-x_{\mathrm{DIF}}\right)\right]-\ln \left[(2 / 3)^{2} \cdot(1 / 3)\right]\right\}
$$

Ideal behavior is represented in Figure 6 by the dotted lines.

\section{$\underline{\text { Diflunisal }+ \text { picolinamide }}$}

The DSC curves shown in Figure 8 for (DIF + PA) mixtures of different composition show a different behavior for mixtures of compositions higher and lower than $x_{\mathrm{DIF}}=0.50$. For $x_{\mathrm{DIF}}=0.50$ a single narrow peak is observed at $T_{\text {fus }}=(459.7 \pm 0.2) \mathrm{K}$ with melting enthalpy $\Delta_{\text {fus }} H_{\mathrm{m}}=(65.8 \pm 2.2) \mathrm{kJ} \cdot \mathrm{mol}^{-1}, n=8$, indicating a $1: 1$ co-crystal formation.

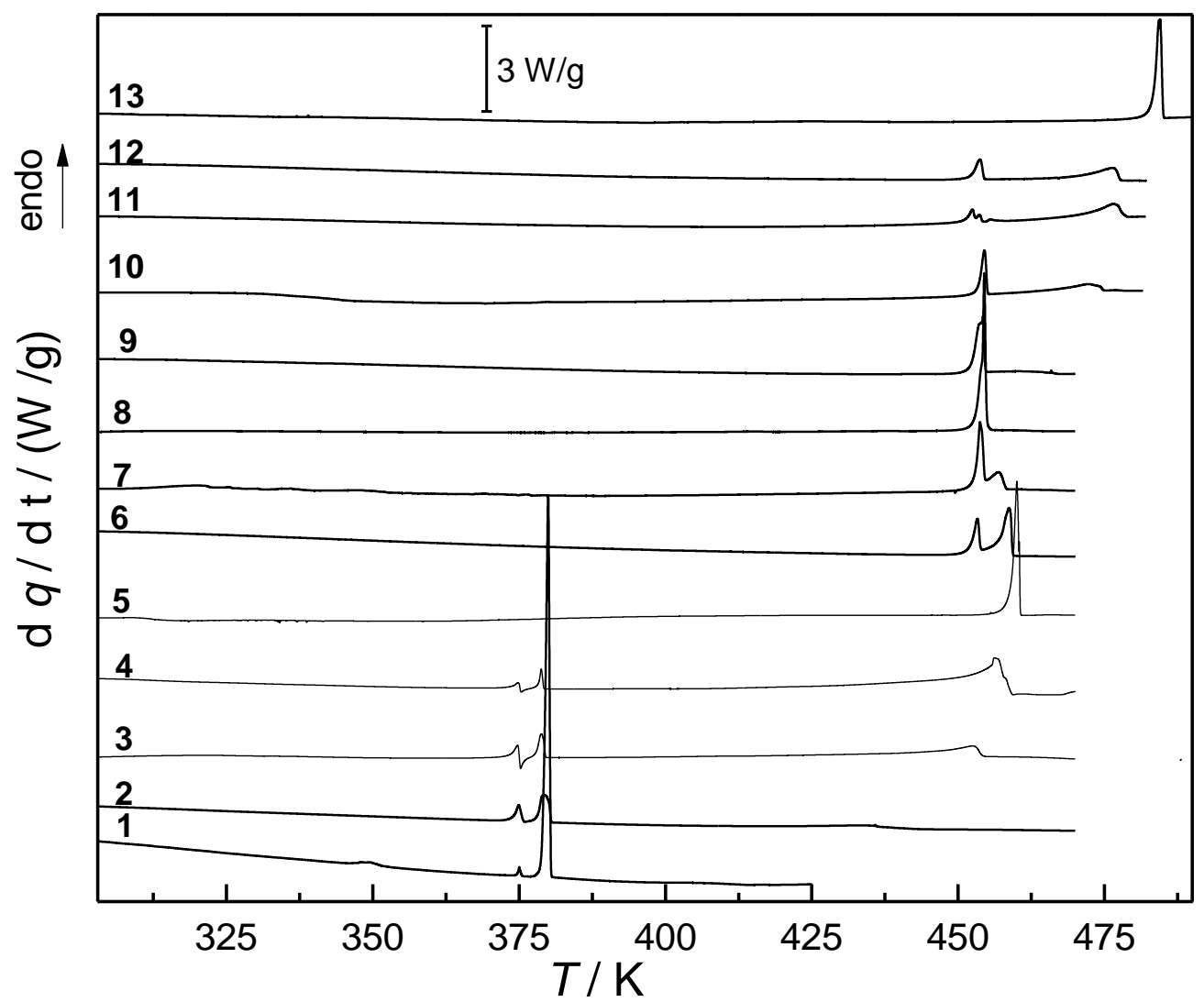

FIGURE 8. DSC heating curves for selected DIF + PA mixtures, $\beta=2 \mathrm{~K} \mathrm{~min}^{-1} \cdot \mathbf{1} \cdot x_{\mathrm{DIF}}=0 ; 2$. $x_{\mathrm{DIF}}$ $=0.1636 ; 3$. $x_{\mathrm{DIF}}=0.3334 ;$ 4. $x_{\mathrm{DIF}}=0.3996 ; \mathbf{5} . x_{\mathrm{DIF}}=0.5000 ; \mathbf{6} . x_{\mathrm{DIF}}=0.5569 ; 7 . x_{\mathrm{DIF}}=0.6061 ; 8$. $x_{\mathrm{DIF}}=0.6557 ;$ 9. $x_{\mathrm{DIF}}=0.7492 ; 10 . x_{\mathrm{DIF}}=0.8547 ; 11 . x_{\mathrm{DIF}}=0.8954 ; 12 . x_{\mathrm{DIF}}=0.8990 ; 13 \cdot x_{\mathrm{DIF}}=$ 1.000 .

The polymorphism of picolinamide is clearly evident in the DSC curves for mixtures with an excess of this substance. Picolinamide, polymorph II, may experiment a solid-solid phase transition to form $\mathrm{I}$ in the heating process at $T \sim 350 \mathrm{~K}$ (Figure 8, curve 1) and melting of I occurs at $T_{\text {fus, I }}=(379.6 \pm 0.4) \mathrm{K}^{41}$. In some experiments, fusion of form II can be observed, $T_{\text {fus,II }}=(375.2 \pm 0.4) \mathrm{K}$, with subsequent crystallization of form I from the 
liquid and melting of $\mathrm{I}^{41}$. The two invariant temperatures registered in the DSC curves of mixtures $(\mathrm{DIF}+\mathrm{PA}), x_{\mathrm{DIF}}<0.50, T_{\mathrm{E} 1}=(373.6 \pm 0.4) \mathrm{K}$ and $T_{\mathrm{E} 2}=(377.7 \pm 0.4) \mathrm{K}$, are ascribable to eutectic mixtures containing picolinamide polymorphs II and I, respectively. Another invariant temperature is observed at $T_{\mathrm{E} 3}=(453.4 \pm 0.9) \mathrm{K}$, for $\mathrm{x}_{\mathrm{DIF}}>0.50$, which is assigned to the eutectic point for the co-crystal and DIF. For $x_{\mathrm{DIF}}>0.5$, mixtures were prepared both by ethanol assisted grinding, EAG, and by neat grinding. For these compositions, DSC curves of EAG mixtures present a more complex profile when compared to neat prepared ones, as exemplified by curves 11 and 12 in Figure 8. This results from the transition, at least in part, of diflunisal polymorph III to form I.

The binary solid-liquid phase diagram of pyridine-2-carboxamide, picolinamide, and diflunisal, derived from DSC curves, is shown in Figure 9. Maximum uncertainties on the temperature values are $\pm 0.8 \%$.

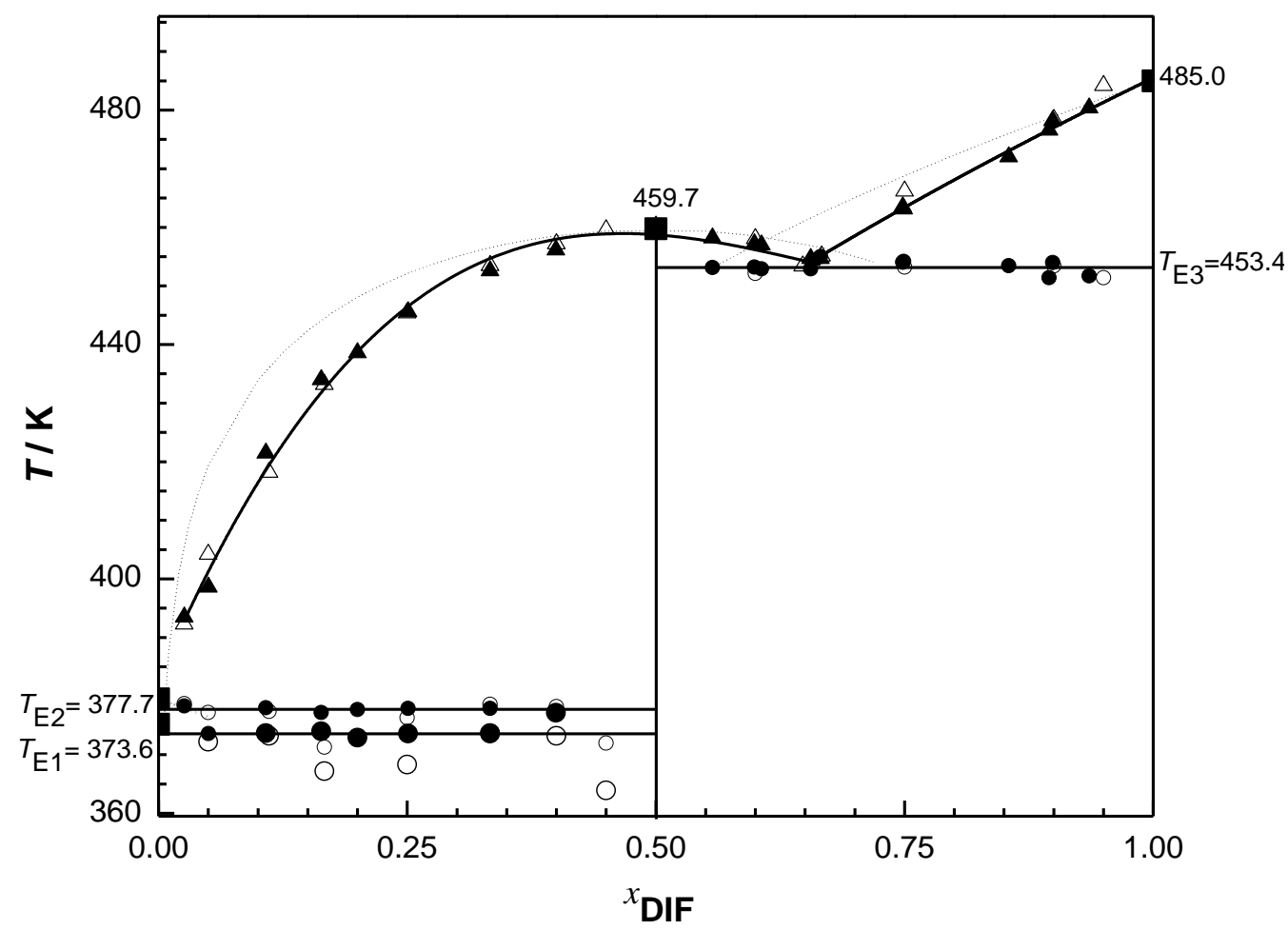

Figure 9. (Solid + liquid) phase diagram of (DIF + PA). $\bullet$, o, eutectic temperature, $\boldsymbol{\Delta}, \Delta$, liquidus temperature, $\mathbf{\square}$, pure compound fusion. (solid symbols, $\beta=2 \mathrm{~K} \cdot \mathrm{min}^{-1}$, empty symbols, $\beta=10$ $\mathrm{K} \cdot \mathrm{min}^{-1}$ ); solid lines are used as guides for the eye; dotted lines represent ideal behavior

It is worth noting that the first eutectic point lies at a composition of almost pure picolinamide. This indicates a very stable co-crystal compared to pure picolinamide. The composition of the eutectic mixture, melting at $T_{\mathrm{E} 3} \sim 453 \mathrm{~K}$, is estimated to be $x_{\mathrm{DIF}}=0.65$ 
from the Tammann plot shown in Figure 10 (Uncertainties in these enthalpy values are at maximum $\pm 5 \%$ ). There is no evidence of solid solution formation both in the vicinity of the co-crystal and of pure diflunisal.

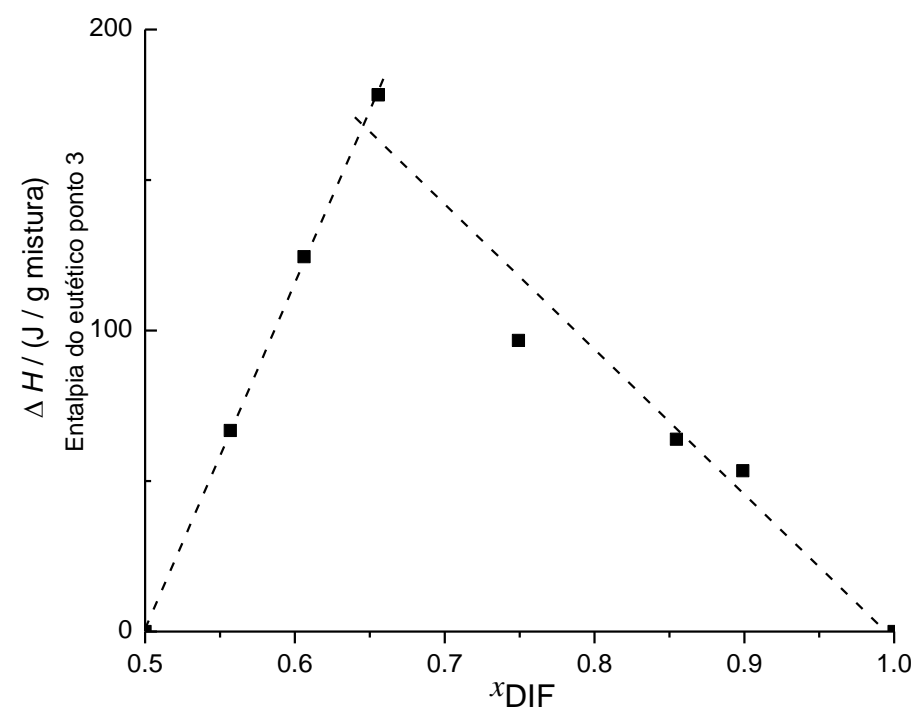

FIGURE 10. Tammann plot for the (diflunisal + picolinamide) system, $x_{\mathrm{DIF}} \geq 0.5000$.

The binary solid-liquid phase diagram of (DIF $+\mathrm{Pa}$ ) shows negative deviation from ideal solution (dotted lines in Figure 9). Equation (4), a modification of equation (3) taking into account the stoichiometry of this particular co-crystal, was used to calculate ideal liquidus temperatures in the neighborhood of the co-crystal, between the two eutectic points.

$$
\frac{1}{T_{f u s}}=\frac{1}{T_{f u s, \mathrm{DIF}: \mathrm{PA}}}-\frac{R}{\Delta_{f u s} H_{m, \mathrm{DIF}: \mathrm{PA}}}\left\{\ln \left[x_{\mathrm{DIF}} \cdot\left(1-x_{\mathrm{DIF}}\right)\right]-\ln 0.25\right\}
$$

Values that range from $\gamma_{\mathrm{DIF}}=0.97$ for $x_{\mathrm{DIF}}=0.9357$ to $\gamma_{\mathrm{DIF}}=0.87$ for $x_{\mathrm{DIF}}=0.7482$, are obtained, from eq.(2), for mixtures richer in diflunisal, indicating also in this system, solution negative deviation from ideal behavior (dotted line in Figure 9). However, deviations from ideality are much lower in this system than for (DIF + INA) system, reflecting lower intermolecular between DIF and PA in the molten phase.

\subsection{XRPD and FTIR characterization}

The XRPD data presented in Figures 11.a and 11.b for the (diflunisal + isonicotinamide) and (diflunisal + picolinamide) systems, respectively, clearly identifies new solid state 
arrangements for the co-crystals, with new reflections when compared to the pure component patterns.
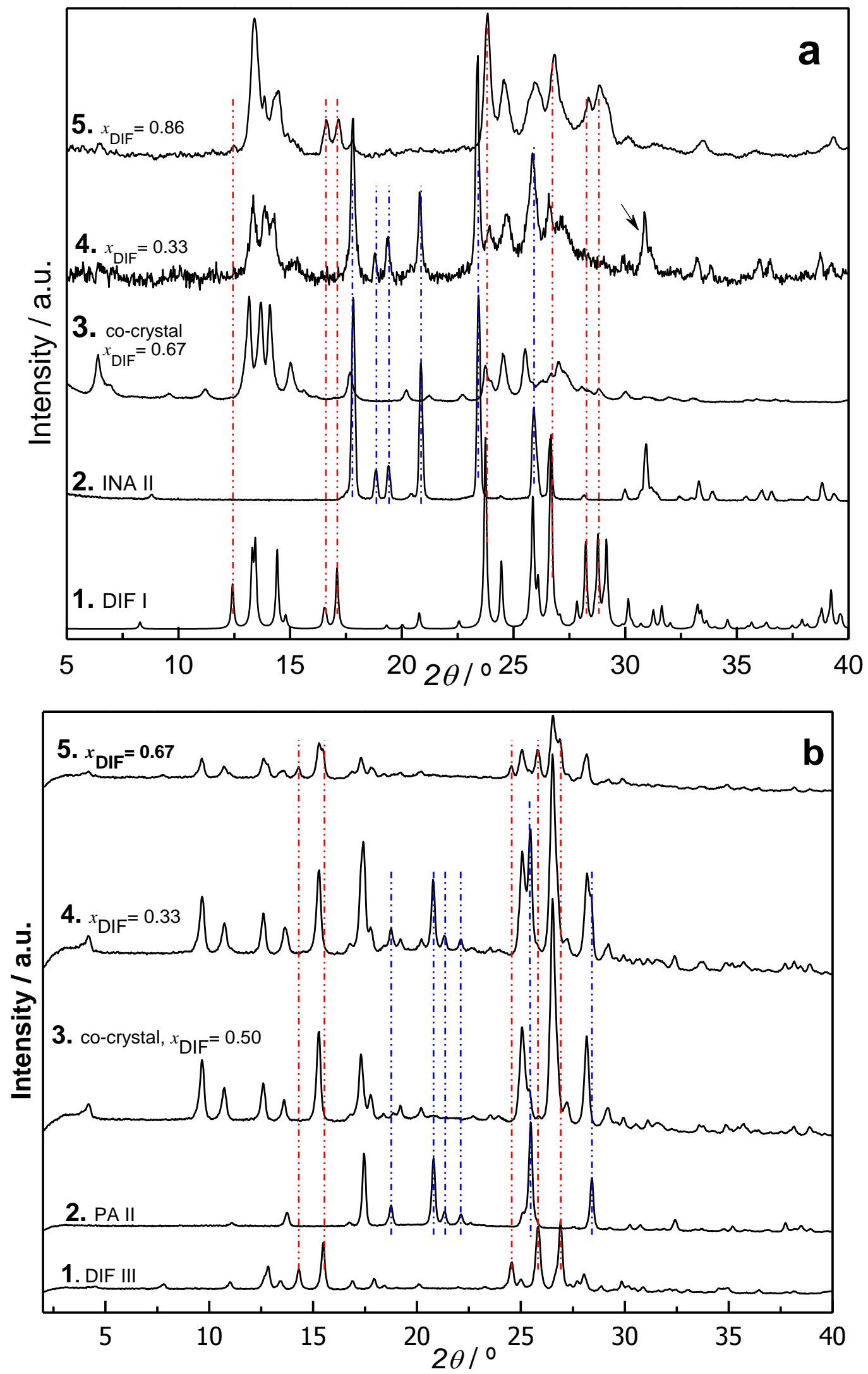

Figure 11. X-ray powder diffractograms a. DIF + INA: 1. DIF, polymorph I; 2. INA, polymorph II; 3. Co-crystal $x_{\mathrm{DIF}}=0.6667$; 4. $x_{\mathrm{DIF}}=0.3323$ (INA II excess, blue dashed lines); 5. $x_{\mathrm{DIF}}=0.8572$ 
(DIF I excess, red dashed lines). b. DIF + PA: 1. DIF, polymorph III; 2. PA, polymorph II; 3. Cocrystal $x_{\mathrm{DIF}}=0.5000 ;$ 4. $x_{\mathrm{DIF}}=0.3334$ (PA II excess, blue dashed lines); 5. $x_{\mathrm{DIF}}=0.6654$ (DIF III excess, red dashed lines ).

In addition, peaks corresponding to the presence of the excess components are clearly seen in figure 12.a for $x_{\mathrm{DIF}}=0.3323$ - INA II excess, $2 \theta=17.8,18.8,19.4,20.8,23.5$, 26.6and $30.9^{\circ}-$ and $x_{\mathrm{DIF}}=0.8572-$ DIF I excess, $2 \theta=12.4,16.6,17.1,23.8,26.7$, 28.3 , and $28.8^{\circ}$. A similar analysis can be made in figure 12.b for $x_{\mathrm{DIF}}=0.3334$ - PA II excess, $2 \theta=18.8,20.8,21.1,21.4,25.5$ and $28.4^{\circ}-$ and $x_{\text {DIF }}=0.6654-$ DIF III excess, $2 \theta$ $=14.4,15.5,24.6,25.9$ and 27.0 ${ }^{\circ}$. A similar comparison is made, in Figures S3 to S5 (supplementary material) using infrared spectra. XRPD data indicates that the $(2: 1)$ diflunisal-isonicotinamide co-crystal synthesized in the current work is the same identified recently by Wang et al. ${ }^{32}$

The FTIR spectra of the co-crystals formed by each of the three pyridinecarboxamide isomers and diflunisal are presented in Figure 12.

The heterosynton formed by acid- $N_{\text {aromatic }}$ groups is identified in the three cocrystals by the characteristics bands at about 2500, 2150 and $1900 \mathrm{~cm}^{-126,57-60}$. There is a reduced number of co-crystals reported in literature using picolinamide as a co-former ${ }^{33}$, ${ }^{39}$. In this isomer, the aromatic nitrogen, ortho relatively to the amide group, is, a priori, less prone to be involved in intermolecular interactions. However, it was observed that the aromatic nitrogen participates in $\mathrm{N}_{\text {amide }}-\mathrm{H}$... $\mathrm{N}_{\text {aromatic }}$ bonds in the crystal lattice of the picolinamide:salycilic acid co-crystal and also in the acid $\mathrm{O}-\mathrm{H} \ldots \mathrm{N}_{\text {aromatic }}$ bond in the cocrystal of picolinamide with adipic acid ${ }^{33}$. The infrared spectrum obtained in the current work points out to picolinamide association with diflunisal involving this latter heterosynthon.

However, in the $\mathrm{NH}_{2}$ elongation region, significant differences are observed between the spectrum of the diflunisal:picolinamide co-crystal and those formed by diflunisal and the 3- and 4-pyridinecarboxamide isomers. The asymmetric elongation band, $v_{\text {as }}\left(\mathrm{NH}_{2}\right)$, appears at $3372 \mathrm{~cm}^{-1}$ and at $3367 \mathrm{~cm}^{-1}$, in INA and in NA, respectively, and in the cocrystals it is shifted to higher energies: $3394 \mathrm{~cm}^{-1}$ for DIF:INA co-crystal and $3406 \mathrm{~cm}^{-1}$ for DIF:NA. A similar behaviour is observed for the symmetric elongation mode, $v_{\mathrm{s}}\left(\mathrm{NH}_{2}\right)$ : $3176 \mathrm{~cm}^{-1}$ in INA and $3209 \mathrm{~cm}^{-1}$ in the co-crystal DIF:INA, $2: 1 ; 3162 \mathrm{~cm}^{-1}$ in nicotinamide and $3229 \mathrm{~cm}^{-1}$ in the co-crystal DIF:NA, 2:1. This blue shift behavior was reported by Desiraju et $a l^{31}$ in the formation of cyclic acid-amide heterodimers and proposed as a marker to identify this synthon in co-crystals. 

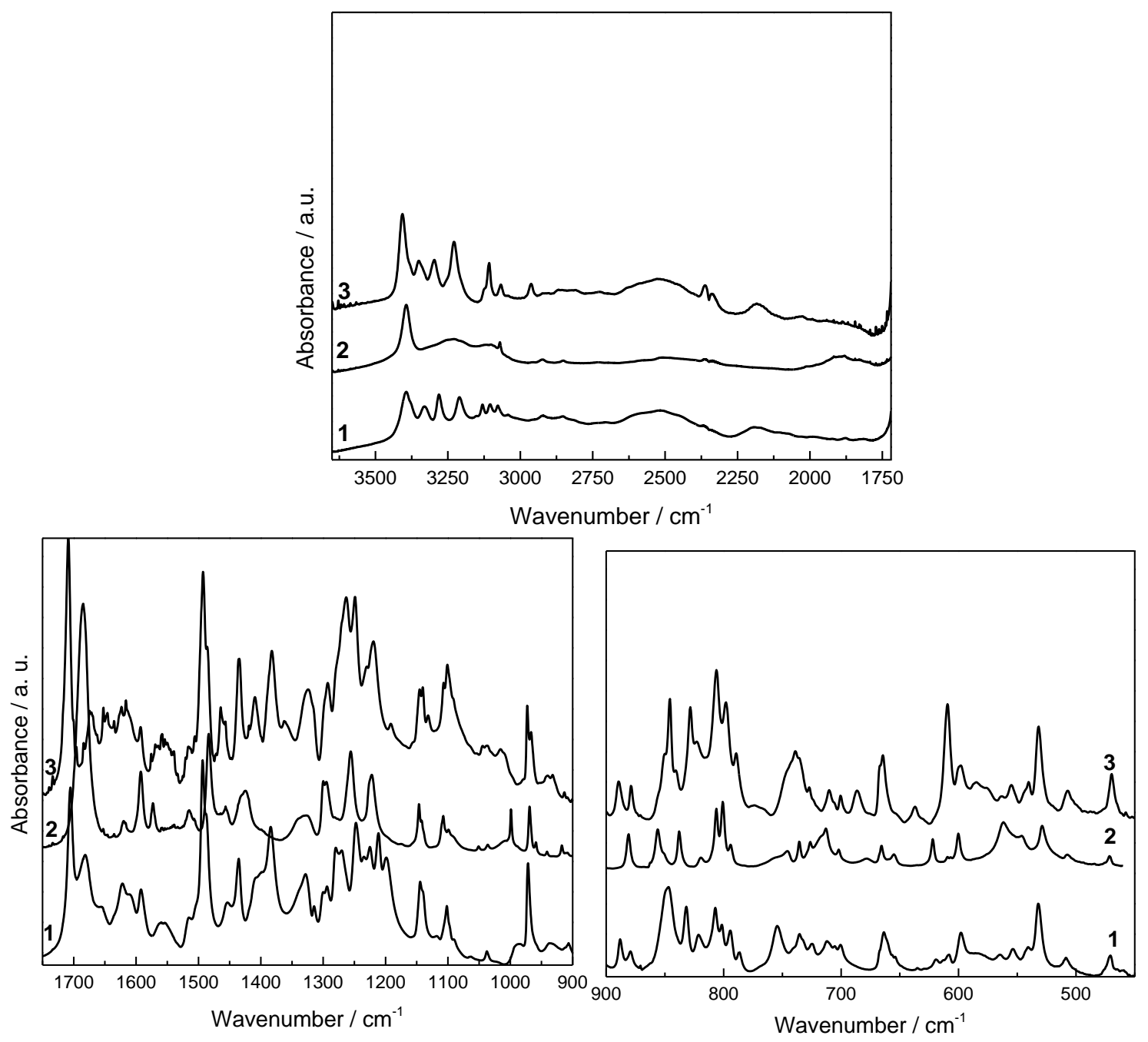

FIGURE 12. FTIR spectra of the co-crystals: 1. DIF + INA (2:1); 2. DIF + PA (1:1); 3. DIF + NA $(2: 1)^{30}$.

In contrast, the IR spectra of the DIF:PA co-crystal are substantially different from those of DIF:INA and DIF:NA. In the DIF:PA co-crystal the asymmetric, $v_{\text {as }}\left(\mathrm{NH}_{2}\right)$, and the symmetric, $v_{\mathrm{s}}\left(\mathrm{NH}_{2}\right)$, elongation modes are redshifted when compared to picolinamide spectrum: $v_{\mathrm{as}}\left(\mathrm{NH}_{2}\right)$ and $v_{\mathrm{s}}\left(\mathrm{NH}_{2}\right)$ have their maxima at 3417 and $3176 \mathrm{~cm}^{-1}$, respectively, in picolinamide, form II, which are shifted to $3394 \mathrm{~cm}^{-1}$ and $3106 \mathrm{~cm}^{-1}$ in the co-crystal. Desiraju et al. ${ }^{60}$ in their attempt to identify synthons in co-crystals and polymorphs using infrared spectroscopy, with a special focus on primary amides, associate deviations of $\mathrm{NH}_{2}$ elongations frequencies to lower energies to the change in association from dimers to chains. Centrosymmetric amide-amide dimers are present in the crystalline structure of picolinamide. From the co-crystal infrared spectrum, and taking into account Desiraju et al. conclusions, the change to chain association is quite plausible. 
The results show that, although co-crystals have been obtained for diflunisal with the three isomeric pyridinecarboxamides, the structural differences of the co-formers have an important influence in the supramolecular association, clearly distinguishing pyridine-2carboxamide from the others.

\subsection{Crystallization experiments}

The ternary phase diagrams DIF-CoF-ethanol, Figure 4, were used to design cocrystallization experiments in order to obtain the pure co-crystals. Solutions of appropriate composition were prepared at $323 \mathrm{~K}$ and then cooled to $298 \mathrm{~K}$. The used solution compositions were chosen in the region marked by $A$ in the diagrams - below line $a-b$ that joins the pure components solubility at $298 \mathrm{~K}$ and also below the co-crystal solubility at $323 \mathrm{~K}$. This procedure allowed the preparation of pure samples of the co-crystals described in this work as confirmed by XRPD and FTIR.

Data presented in Figure 4, combined with the known co-crystals stoichiometry, allow the construction of the complete triangular ternary phase diagrams, at $T=298 \mathrm{~K}$, presented in Figures 13 and 14. Pure co-crystals can also be obtained starting from solution (region 4 in the diagram) and evaporating the solvent, at constant temperature, until region 1 is reached.
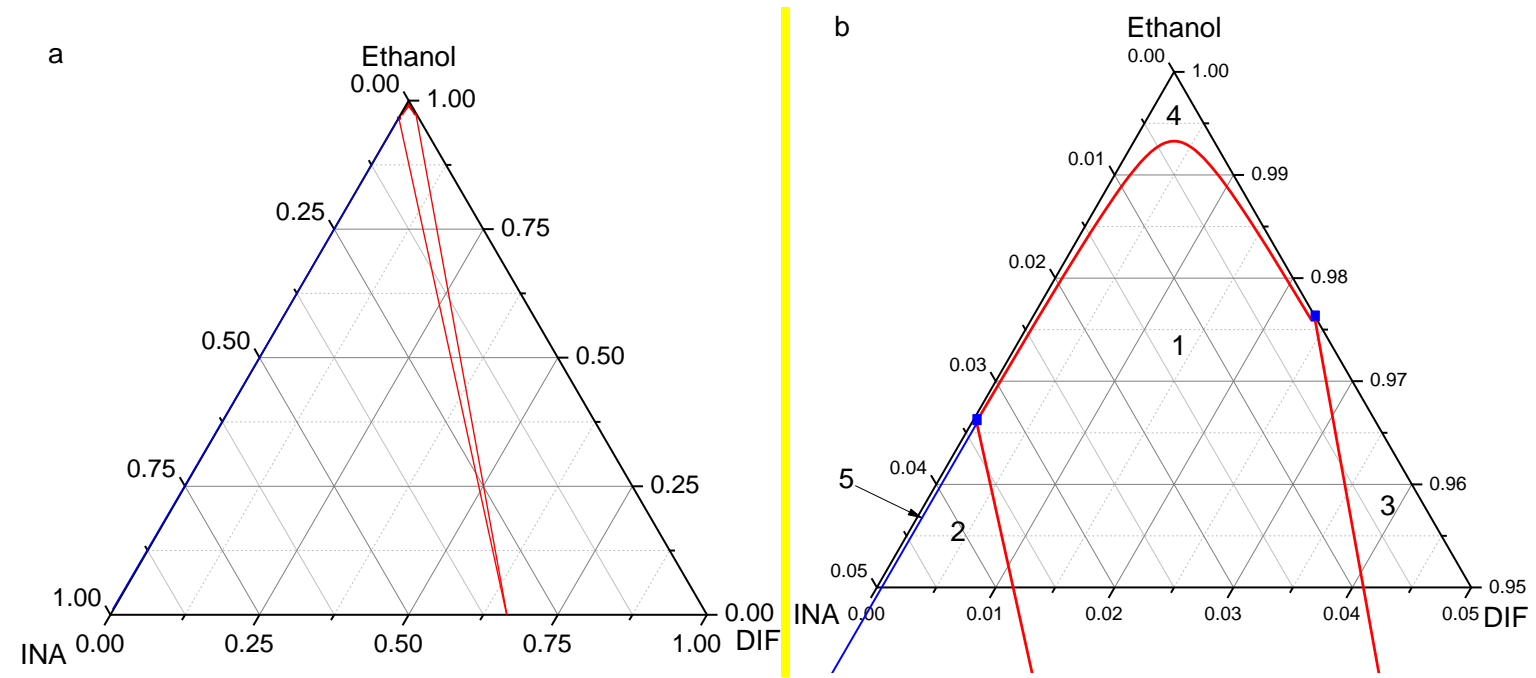

FIGURE 13. Ternary phase diagram of diflunisal-isonicotinamide-ethanol at $T=298 \mathrm{~K}$. equilibrium phases in the diagram: 1. co-crystal+liquid; 2. INA+co-crystal+liquid; 3. DIF+cocrystal+liquid; 4. liquid; 5. INA+liquid. 


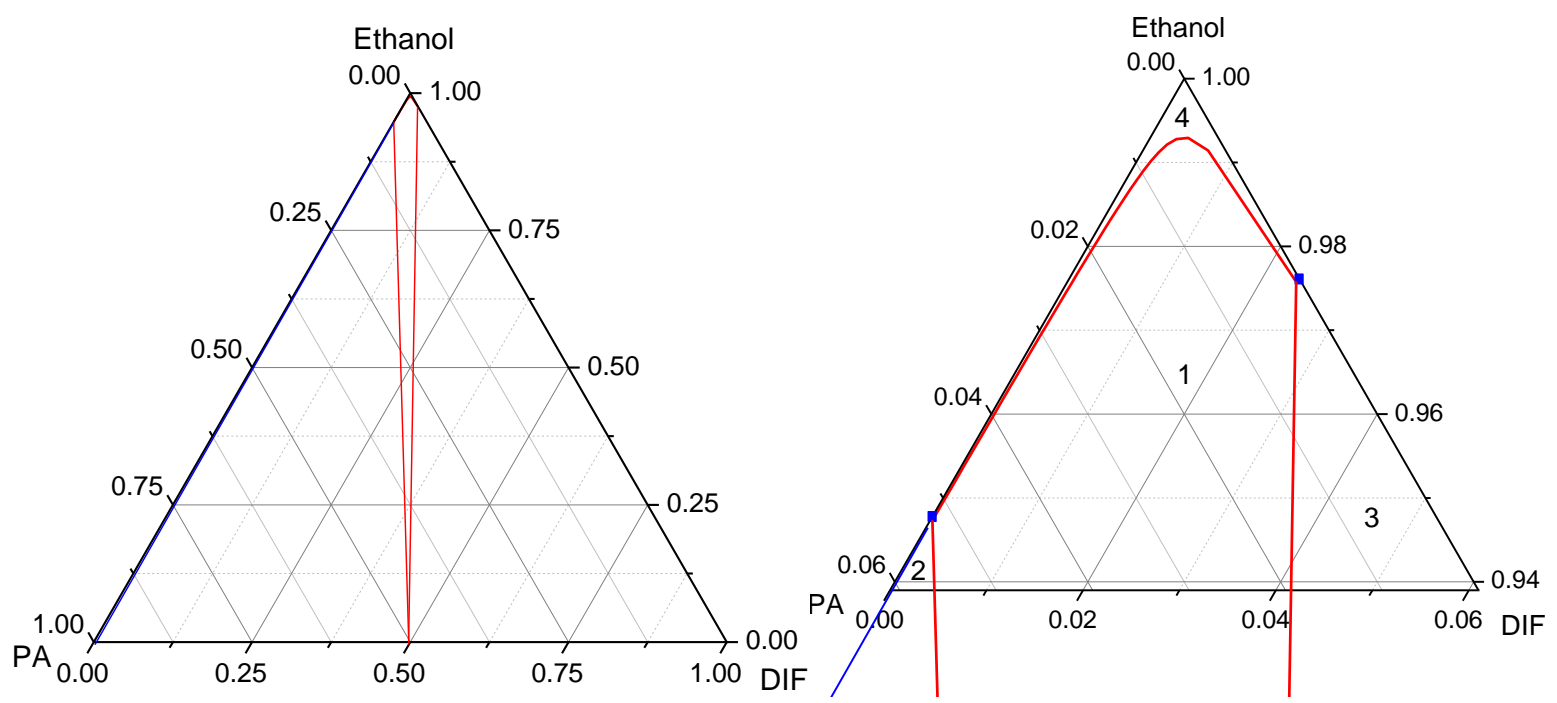

FIGURE 14. Ternary phase diagram of diflunisal-picolinamide-ethanol at $T=298 \mathrm{~K}$. equilibrium phases in the diagram: 1. co-crystal+liquid; 2. PA+co-crystal+liquid; 3. DIF+cocrystal+liquid; 4. Liquid.

Although the pure co-crystals were generated in the co-crystallization processes designed by the ternary phase diagrams, powder samples were always obtained. No single crystals, suitable for structure determination, could be produced, which, unfortunately, is not uncommon in the synthesis of co-crystals.

Subsequent experiments carried out in order to obtain single crystals of the two identified co-crystals were unsuccessful: crystallization from various solvents, methanol, 1-butanol, acetone, ethyl acetate, ethyleneglycol diethylether, tetrahydrofuran, acetonitrile, dimethylsulfoxide, $p$-xylene, with supersaturation achieved in different ways, and also with seeding with the co-crystals obtained by grinding was tried; crystallization from gel media was also tested ${ }^{61}$.

\section{Conclusions}

The thermodynamic approach used in the current work successfully predicts cocrystal formation between diflunisal and picolinamide and isonicotinamide, as it was found before for the other pyridinecarboxamide isomer, nicotinamide ${ }^{30}$ and despite the differences of the co-former molecular structures. The solid-liquid binary phase diagrams give conclusive evidence of co-crystals formation and of their stoichiometry: a (1:1) cocrystal with picolinamide, and a $(2: 1)$ co-crystal with isonicotinamide. The determined ternary phase diagrams enable the design of co-crystallization processes. 
Differences in the association between pyridine-2-carboxamide and diflunisal relatively to the other two pyridinecarboxamide isomers are clearly evidenced by the infrared spectra. In opposition to pyridine-3-carboxamide and pyridine-4carboxamide:diflunisal co-crystals, which share significant structural similarities, at least in what concerns the supramolecular synthons, different heterosynthons involving the $\mathrm{NH}_{2}$ group are expected in the diflunisal + pyridine-2-carboxamide co-crystal.

Two binary eutectic mixtures, potentially relevant for pharmaceutical applications, are identified from the solid-liquid binary phase diagram investigations (DIF:INA, $x_{\mathrm{DIF}}=0.20$ and DIF:PA, $\left.x_{\mathrm{DIF}}=0.65\right)$.

Acknowledgements: The Coimbra Chemistry Centre is supported by the Fundação para a Ciência e a Tecnologia (FCT), Portuguese Agency for Scientific Research, through the project PEst-OE/QUI/UI0313/2014. This work was also supported in part by the EU COST Action CM1402 "Crystallize”.

A.O.L.E. acknowledges FCT, Programa Ciência Global SFRH/BD/51480/2011, for financial support. A.O.L.E. highly appreciates the hospitality that he received during his visit to the crystallization group of J.t.H. at the Delft University of Technology.

\section{REFERENCES}

1. Regulatory Classification of Pharmaceutical Co-Crystals, http://www.fda.gov/downloads/Drugs/.../Guidances/UCM281764.pdf, (accessed February 2016).

2. G. R. Desiraju, CrystEngComm, 2003, 5, 466-467.

3. A. D. Bond, CrystEngComm, 2007, 9, 833-834.

4. J. D. Dunitz, CrystEngComm, 2003, 5, 506-506.

5. P. Vishweshwar, J. A. McMahon, J. A. Bis and M. J. Zaworotko, J. Pharm. Sci., 2006, 95, 499-516.

6. H. G. Brittain, J. Pharm. Sci., 2013, 102, 311-317.

7. K. B. Landenberger, O. Bolton and A. J. Matzger, Angew. Chem. Int. Ed., 2013, 52, 64686471.

8. D. D. Bucar, S. Filip, M. Arhangelskis, G. O. Lloyd and W. Jones, CrystEngComm, 2013, 15, 6289-6291.

9. J. Wouters and L. Quéré, Pharmaceutical Salts and Co-crystals, Royal Society of Chemistry, London, 2012. 
10. N. A. Meanwell, in Annu. Rep. Med. Chem., ed. E. M. John, Academic Press, 2008, vol. Volume 43, pp. 373-404.

11. A. O. L. Evora, R. A. E. Castro, T. M. R. Maria, M. T. S. Rosado, M. Ramos Silva, A. Matos Beja, J. Canotilho and M. E. S. Eusebio, Cryst. Growth Des., 2011, 11, 4780-4788.

12. H. G. Brittain, J. Pharm. Sci., 2013, 102, 311-317.

13. H. Juncher and F. Raaschou, Antibiotic Med Clin Ther, 1957, 4, 497-507.

14. O. Almarsson and M. J. Zaworotko, Chem. Commun., 2004, DOI: 10.1039/b402150a, 18891896.

15. C. A. Lipinski, J. Pharmacol. Toxicol. Methods, 2000, 44, 235-249.

16. M. K. Stanton and A. Bak, Cryst. Growth Des., 2008, 8, 3856-3862.

17. A. Bak, A. Gore, E. Yanez, M. Stanton, S. Tufekcic, R. Syed, A. Akrami, M. Rose, S. Surapaneni, T. Bostick, A. King, S. Neervannan, D. Ostovic and A. Koparkar, J. Pharm. Sci., 2008, 97, 3942-3956.

18. D. P. McNamara, S. L. Childs, J. Giordano, A. Iarriccio, J. Cassidy, M. S. Shet, R. Mannion, E. O'Donnell and A. Park, Pharm. Res., 2006, 23, 1888-1897.

19. A. M. Chen, M. E. Ellison, A. Peresypkin, R. M. Wenslow, N. Variankaval, C. G. Savarin, T. K. Natishan, D. J. Mathre, P. G. Dormer, D. H. Euler, R. G. Ball, Z. Ye, Y. Wang and I. Santos, Chem. Commun., 2007, 419-421.

20. T. L. Lemke, D. A. Williams, V. F. Roche and S. W. Zito, Foye's Principles of Medicinal Chemistry, Wolters Kluwer Health, Lippincott Williams \& Wilkins, Philadelphia, 6th edn., 2008.

21. N. K. Duggirala, M. L. Perry, O. Almarsson and M. J. Zaworotko, Chem. Commun., 2016, 52, 640-655.

22. T. Takagi, C. Ramachandran, M. Bermejo, S. Yamashita, L. X. Yu and G. L. Amidon, Mol. Pharm., 2006, 3, 631-643.

23. T. Dorn, K. M. Fromm and C. Janiak, Aust. J. Chem., 2006, 59, 22-25.

24. L. Nigond, N. Condamines, P. Y. Cordier, J. Livet, C. Madic, C. Cuillerdier, C. Musikas and M. J. Hudson, Sep. Sci. Technol., 1995, 30, 2075-2099.

25. S. Cherukuvada and A. Nangia, CrystEngComm, 2012, 14, 2579-2588.

26. S. Cherukuvada and A. Nangia, Chem. Commun., 2014, 50, 906-923.

27. Tablets Dolobid ${ }^{\circledR}$

(Diflunisal) http://www.accessdata.fda.gov/drugsatfda docs/label/2007/018445s058lbl.pdf, (accessed January 2016).

28. J. L. Berk, O. B. Suhr, Y. Sekijima, T. Yamashita, M. Heneghan, S. R. Zeldenrust, Y. Ando, S.i. Ikeda, P. Gorevic, G. Merlini, J. W. Kelly, M. Skinner, A. B. Bisbee, P. J. Dyck, L. Obici and C. Familial Amyloidosis, Amyloid: J. Prot. Fold. Disord., 2012, 19, 37-38.

29. C. C. Seaton, A. Parkin, C. C. Wilson and N. Blagden, Cryst. Growth Des., 2009, 9, 47-56.

30. A. O. L. Évora, R. A. E. Castro, T. M. R. Maria, M. R. Silva, J. H. ter Horst, J. Canotilho and M. E. S. Eusébio, Int. J. Pharm., 2014, 68-75.

31. A. O. L. Évora, R. A. E. Castro, T. M. R. Maria, M. T. S. Rosado, M. R. Silva, J. Canotilho and M. E. S. Eusébio,Binary solid-liquid phase diagrams of diflunisal and pyridinecarboxamides, JEEP XXXVIII, Journées d'Étude des Equilibres entre Phases, Rouen, 2012.

32. L. Wang, B. Tan, H. Zhang and Z. Deng, Org. Process Res. Dev., 2013, 17, 1413-1418.

33. H. C. S. Chan, G. R. Woollam, T. Wagner, M. U. Schmidt and R. A. Lewis, Crystengcomm, 2014, 16, 4365-4368.

34. M. Habgood, M. A. Deij, J. Mazurek, S. L. Price and J. H. ter Horst, Cryst. Growth Des., 2010, 10, 903-912.

35. R. A. Chiarella, R. J. Davey and M. L. Peterson, Cryst. Growth Des., 2007, 7, 1223-1226.

36. K. Chadwick, R. Davey, G. Sadiq, W. Cross and R. Pritchard, CrystEngComm, 2009, 11, 412414.

37. J. H. ter Horst, M. A. Deij and P. W. Cains, Cryst. Growth Des., 2009, 9, 1531-1537. 
38. J. Holan, F. Stepanek, P. Billot and L. Ridvan, Eur. J. Pharm.Sci., 2014, 63, 124-131.

39. R. A. E. Castro, J. D. B. Ribeiro, T. M. R. Maria, M. Ramos Silva, C. Yuste-Vivas, J. Canotilho and M. E. S. Eusebio, Cryst. Growth Des., 2011, 11, 5396-5404.

40. W. I. Cross, N. Blagden, R. J. Davey, R. G. Pritchard, M. A. Neumann, R. J. Roberts and R. C. Rowe, Cryst. Growth Des., 2003, 3, 151.

41. A. O. L. Evora, R. A. E. Castro, T. M. R. Maria, M. T. S. Rosado, M. Ramos Silva, J. Canotilho and M. E. S. Eusebio, CrystEngComm, 2012, 14, 8649-8657.

42. T. Takano, Y. Sasada and M. Kakudo, Acta Crystallogr., 1966, 21, 514-\&.

43. C. B. Aakeroy, A. M. Beatty, B. A. Helfrich and M. Nieuwenhuyzen, Cryst. Growth Des., 2003, 3, 159.

44. K. S. Eccles, R. E. Deasy, L. Fabian, D. E. Braun, A. R. Maguire and S. E. Lawrence, CrystEngComm, 2011, 13, 6923-6925.

45. J. Li, S. A. Bourne and M. R. Caira, Chem. Commun., 2011, 47, 1530-1532.

46. S. A. Kulkarni, E. S. McGarrity, H. Meekes and J. H. ter Horst, Chem. Commun., 2012, 48, 4983-4985.

47. R. Sabbah, X. W. An, J. S. Chickos, M. L. P. Leitao, M. V. Roux and L. A. Torres, Thermochim. Acta, 1999, 331, 93-204.

48. G. Della Gatta, M. J. Richardson, S. M. Sarge and S. Stolen, Pure Appl. Chem., 2006, 78, 1455-1476.

49. Guidance for Industry: Regulatory Classification of Pharmaceutical Co-Crystals, http://www.fda.gov/downloads/Drugs/Guidances/UCM281764.pdf, ${ }_{\text {, }}$ (accessed

February 2016).

50. Reflection paper on the use of cocrystals and other solid state forms of active substances in medicinal products, http://www.ema.europa.eu/docs/en GB/document library/Scientific guideline/2015/07 WC500189927.pdf, (accessed February 2016).

51. Y. Corvis, P. Negrier, M. Lazerges, S. Massip, J.-M. Leger and P. Espeau, J. Phys. Chem. B, 2010, 114, 5420-5426.

52. L. S. Kang, H. W. Jun and J. W. McCall, Int. J. Pharm., 2000, 206, 35-42.

53. G. W. H. Hohne, H. K. Cammenga, W. Eysel, E. Gmelin and W. Hemminger, Thermochim. Acta, 1990, 160, 1.

54. H. E. Gallis and J. C. vanMiltenburg, Thermochim. Acta, 1996, 274, 223.

55. T. Le Minh, J. Von Langermann, H. Lorenz and A. Seidel-Morgenstern, J. Pharm. Sci., 2010, 99, 4084-4095.

56. I. Prigogine and R. Defay, Chemical Thermodynamics, Longmans, Green and Co, Glasgow, 1954.

57. C. S. Cassidy, L. A. Reinhardt, W. W. Cleland and P. A. Frey, J. Chem. Soc., Perkin Trans. 2, 1999, 635-641.

58. J. P. Castaneda, G. S. Denisov, S. Y. Kucherov, V. M. Schreiber and A. Shurukhina, J. Mol. Struct., 2003, 660, 25-40.

59. D. Hadzi and Kobilaro.N, J. Chem. Soc. A, 1966, 439-\&.

60. A. Mukherjee, S. Tothadi, S. Chakraborty, S. Ganguly and G. R. Desiraju, CrystEngComm, 2013, 15, 4640-4654.

61. D. Choquesillo-Lazarte and J. Manuel Garcia-Ruiz, Journal of Applied Crystallography, 2011, 44, 172-176. 
Co-crystals of diflunisal and isomeric pyridinecarboxamides - a thermodynamics and crystal engineering contribution

António O. L. Évora, ${ }^{a}{ }^{*}$ Ricardo A. E. Castro, ${ }^{\mathrm{b}}$ Teresa M. R. Maria, ${ }^{\mathrm{a}}$ M. Ramos Silva, ${ }^{\mathrm{c}}$ J. H. ter Horst, ${ }^{\mathrm{d}}$ João Canotilho ${ }^{\mathrm{b}}$ and M. Ermelinda S. Eusébio ${ }^{\mathrm{a}}$

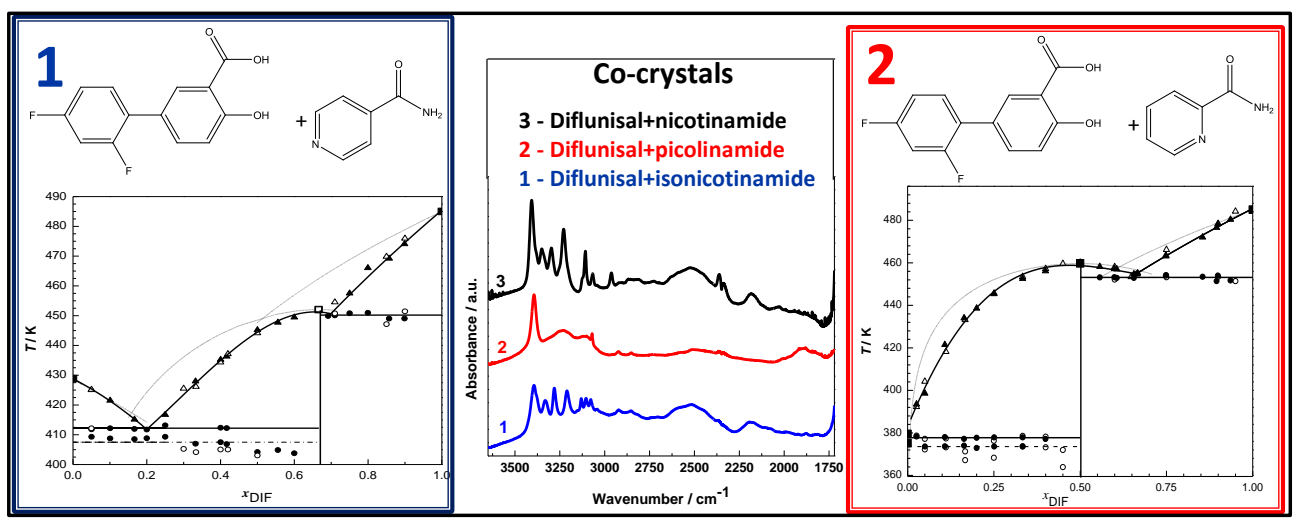

